\title{
La declaración de Jacinto Canek, |76I
}

$\mathrm{E}$ n el año de 1761 la provincia de Yucatán fue el escenario de una importante rebelión indígena, que aunque fue planificada con antelación estalló con premura el día 19 de noviembre en el pueblo de Cisteil, visita del curato de Tixcacaltuyub. Este evento, conocido en la historia como la sublevación de Jacinto Canek, marcó un cambio sustancial en el modelo de la resistencia de los mayas yucatecos frente al colonialismo español, que hasta las primeras décadas del siglo XVIII privilegiaba la huida a los territorios libres del sur y del oriente peninsular, zona de emancipación desde donde los rebeldes animaban intentos de sublevación. Después de la conquista de los itzaes del Petén en 1696, diversos cambios en la estructura socioeconómica y política de la provincia influyeron directamente en el traslado de la confrontación al área de los pueblos bajo campana. Entre los más determinantes se encuentran: el dinámico proceso de usurpación de las tierras comunales y patrimoniales de los pueblos y de los linajes, el desarrollo de una economía fincada en las haciendas ganaderas y agrícolas de los españoles con la consiguiente ampliación del peonaje asalariado y la pérdida paulatina del poder de los caciques y principales sobre la población macehual que acompañó el deterioro de los pueblos como entidades corporativas.

El principal líder de la rebelión fue un indígena originario del barrio de Laboríos de San Francisco Campe- chuelo de la villa y puerto de Campeche, quien después de retornar de un viaje al Petén se proclamó rey nativo y escogió el pueblo de Cisteil para hacerse coronar con el simbólico nombre de José Jacinto Uc de los Santos Canek Chichan Moctezuma, en el que, entre otras cosas, adoptó el linaje de los últimos reyes de los itzaes libres. La muerte de un comerciante español por los rebeldes de Cisteil el citado 19 de noviembre precipitó los acontecimientos, pues al día siguiente un grupo de 15 milicianos de Sotuta que acudieron a la represión de los alzados fue atacado y la mayoría de sus integrantes muertos, incluyendo el capitán Tiburcio Cosgaya.

En los días siguientes llegaron al pueblo rebelde diversos caciques y principales a otorgar la obediencia al nuevo rey llevándole regalos y acompañados de grupos de hombres armados con escopetas, machetes y palos ahusados. El día 20 se celebró la entronización del rey indígena en una concurrida ceremonia en la que se empleó la corona y manto de la imagen de la Virgen María. En una semana, entre 1200 y 2500 mayas se congregaron en Cisteil bajo las ordenes de Canek, quien abolió los tributos y repartimientos y nombró un gobierno de mayas libres.

Del otro lado de la frontera étnica, los milicianos españoles de prácticamente todos los partidos de la provincia establecieron un cerrado cerco sobre el pueblo rebelde con cerca de 3 ooo hombres armados de arcabuces y es-

Desacatos, núm. 13, invierno 2003, pp. 163-169. 
copetas y el día 26 por la tarde un contingente de 500 milicianos al mando del capitán Cristóbal Calderón atacó las defensas de los alzados con la ayuda de tres descargas de un cañón de campaña. A la derrota siguió la huida y Canek, con un grupo de seguidores, buscó refugio en la sabana de Sibac, en donde fue capturado el día 30 del mismo mes y conducido a la cárcel de la ciudad de Mérida. El rey nativo compareció ante el gobernador José Crespo y Honorato los días 8 y 9 de diciembre y el 11 le fue dictada la sentencia de muerte, que se ejecutó en la plaza pública de Mérida el día 14. Fue atenazado, se le quebraron los brazos y las piernas a golpes y después de muerto se le mantuvo en el cadalso por tres horas para escarnio de su pueblo. Luego, en las afueras de la ciudad, se quemó su cuerpo y sus cenizas se dieron al viento.
A pesar de la derrota sufrida, en la sublevación de Jacinto Canek se hizo evidente y, sobre todo, se renovó un fuerte sustrato de la cosmovisión maya, especialmente la concepción cíclica del tiempo y de la historia que se puso de manifiesto por medio de las profecías o vaticinios de la rueda de los katunes (13 periodos de 20 años que se repiten ininterrumpidamente). Así, el líder rebelde aseguraba - como había sucedido en rebeliones pasadashaber llegado el tiempo propicio para expulsar o exterminar a los españoles. Pero en este movimiento radical de resistencia también afloró y se reprodujo un antiquísimo mito de origen mesoamericano: el regreso de un hombre-dios, al que se puede identificar con Quetzatcóatl o Kukulkán. Numerosos indicios demuestran que para los mayas que acudieron al llamado de los conjurados de

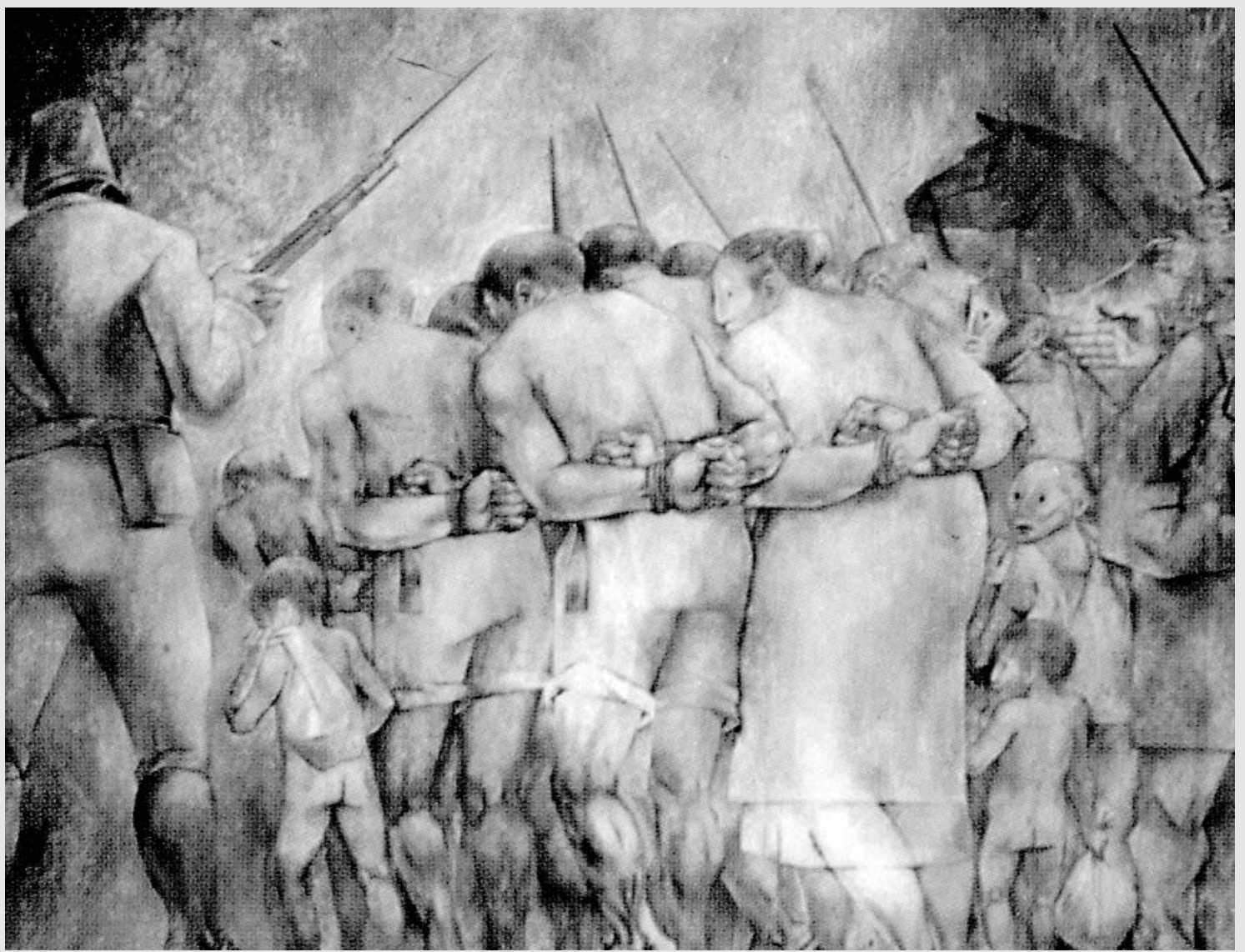

Fernando Castro Pacheco, Venta de indios. 
Cisteil el proclamado rey nativo era una especie de deidad con poderes sobrenaturales para enfrentar a sus enemigos y su estrecho vínculo con el héroe cultural mesoamericano se hace evidente cuando el mismo Canek declaró haber llegado del oriente a redimir a su pueblo.

En el Archivo General de Indias en Sevilla se conservan los autos criminales que el gobernador Crespo levantó en contra de los rebeldes mayas seguidores de Canek. Estos documentos se encuentran en el legajo 3050 del ramo Audiencia de México y están organizados en dos partes. La primera lleva por encabezado: Año de 1761, Testimonio de autos hechos sobre la sublevación que hicieron varios pueblos de esta provincia en el de Cisteel, en el cual aclamaron por rey a Joseph Jacinto Uc de los Santos Canek indio natural del barrio de Campechuelo en el puerto de San Francisco de Campeche, y cubre del 20 de noviembre al 16 de diciembre de 1761 con un total de 208 fojas. La segunda parte se denomina: Autos criminales seguidos de oficio de la real justicia sobre la sublevación que los indios del pueblo de Kisteel y los demás que convocaron hicieron contra ambas majestades el día 19 de noviembre de 1761. En ella se contiene una copia de los documentos incluidos en la parte anterior así como otros que culminan el 18 de febrero de 1762 , que suman 348 fojas. He seleccionado como "Testimonio" para este número de Desacatos la declaración del rey indígena, ya que se trata de un documento de primer orden para acercarnos a uno de los episodios más famosos pero menos comprendidos de la historia indígena del Yucatán colonial. Debo advertir que en la transcripción fue modernizada la grafía y que se actualizaron los nombres de los pueblos tal y como ahora se usan.

PEDRO BRACAMONTE Y SOSA

\section{AGI, México 3050, Declaración del rey Joseph Jacinto Uc de los Santos Canek, Mérida a 8 y 9 de diciembre de 1761, ff. 542r-549r, 180r-187r.}

Declaración de Joseph Jacinto Uc de los Santos Canek rey.

En la ciudad de Mérida a ocho de diciembre de mil setecientos sesenta y uno los señores gobernador y capitán general y su teniente en prosecución de esta causa se constituyeron en la real cárcel pública de esta ciudad, hicieron comparecer a un hombre de quien presente yo el escribano mayor de gobierno mediante lengua de dicho intérprete, recibieron juramento que hizo por Dios nuestro señor y una santa cruz en forma de derecho, so cargo de él prometió decir verdad en lo que supiere, al cual se le hicieron las preguntas siguientes:

Preguntado cómo se llama, de dónde es natural y vecino, qué edad, estado y oficio tiene, dijo: llamarse Joseph Jacinto Uc de los Santos Canek, natural del barrio Campechuelo de los laboríos, que no es vecino de pueblo alguno porque se ha andado vagamundando y que es de edad de treinta años y que es viudo, que el oficio que tenía era el de mayordomo del señor Jesús Nazareno. Y responde.

Preguntado quién le prendió, de cuya orden, en dónde, cuándo y porqué causa, dijo: que lo prendieron los españoles yendo para Tiholop, que no sabe de cuya orden, que no se acuerda qué día pero se acuerda que ha nueve días, según dicha cuenta fue el día treinta del pasado mes de noviembre. Que la causa de su prisión es porque habiéndose salido de Chikindzonot, por unos azotes que le dieron por paseador, llegó el día tres o cuatro de noviembre al pueblo de Cisteil habiendo pasado antes un domingo por Tiholop en donde habló al cacique don Andrés Ku y al escribano y demás justicias a quienes dijo que venía del Oriente rey Jacinto de los Santos 


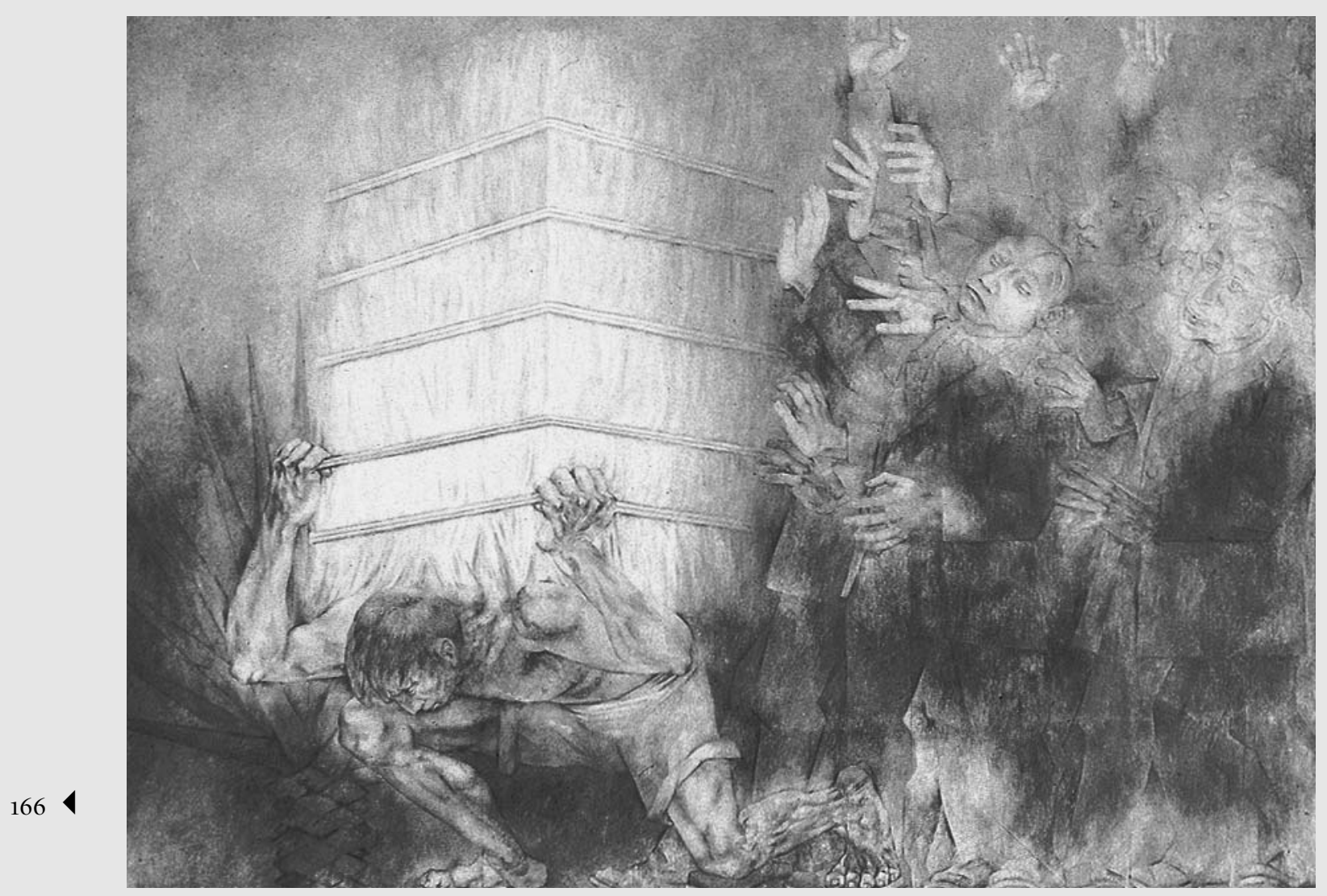

Fernando Castro Pacheco, El henequén.

Uc Canek que iba a coronarse al pueblo de Cisteil por rey de toda la provincia porque ya se había llegado el día de que muriesen todos los españoles y que así estuviesen prontos con todos los indios para cuando se les pidiese. Que le respondió dicho cacique que se fuese y que se coronase y que le regaló una camisa y calzón. Que luego que llegó a Cisteil pidió tres libras de cera para hacer una novena a Nuestra Señora, que después indujo a los indios para que lo coronasen rey porque él lo era legítimo, que había venido del Oriente, que lo trajo un barco inglés y que luego que lo echaron en tierra se volvió con el mismo nombre que lleva dicho. Que con efecto los indios lo aclamaron por rey de esta provincia y mandó publicar, de palabra, con el teniente de dicho Cisteil que matasen todos los cochinos que hubiesen en todo el pueblo, porque los cochinos eran alma de españoles y que matasen a los que viniesen al pueblo. Y que el jueves diez y nueve de noviembre, por la mañana, llegó a las casas reales un tratante a quien fue el confesante y le dijo que si no sabía que aquellas casas reales no eran suyas y por qué había venido a ellas. Y que habiéndole respondido que si se chanceaba, que aquellas casas reales eran para los españoles, que él no venía a hacer mal a nadie, que sólo venía a cobrar sus memoritas, a lo que le respondió el confesante — ahora verás cómo te mato. Y pidiendo una escopeta le disparó y no habiéndole dado fuego le dio dicha escopeta a otro indio alguacil diciéndole —mata 
a este español, y que dicho indio lo mató, que desde allí empezó a gritar diciendo —ya veis cómo mato a los españoles.

Y juntádose todos los indios del pueblo se fueron a casa del fiscal donde estaba de huésped el confesante, que de allí todos juntos se fueron a la iglesia y sacaron del altar a Nuestra Señora y señor San Joseph y los condujeron a la casa del fiscal en donde el confesante se sentó en una silla y le quitó la corona de Nuestra Señora y se coronó con ella y asimismo quitó el manto a Nuestra Señora y se lo puso al hombro. Y que entonces todos los indios de Cisteil le dieron obediencia aclamándole por rey de la provincia, y también mandó recoger todos los recibos de tributos y los rompió.

Que después mandó bajar cuatro calabazas de Castilla y las hizo en dulce, que se comieron y que habiendo fregado la olla, aquella aguaza la echó en el cáliz y les dijo a sus vasallos que con aquella había de ungir a los indios que muriesen para que resucitasen. Y que el viernes veinte por la mañana llevaron a Nuestra Señora y señor San Joseph al convento y los pusieron en el cuarto donde dormían los padres y que él se quedó viviendo en dicho convento que declaró por su palacio. Que también dijo a los indios que Nuestra Señora era esposa del señor San Joseph y que también era su mujer por ser rey de la tierra. Y responde.

Preguntado a cuántos pueblos de esta provincia escribió pidiéndoles ayuda para matar a los españoles, diga los nombres de los caciques y si admitieron, dijo: que los pueblos que convocó fueron los de Tahdziú, Tiholop, Ichmul, Tinum, Tixméuac, Tahdzibilchén, Chacsinkín, Huntulchac y Nenelá, que no todos los caciques concurrieron pero que sí indios de todos, que el de Tiholop tiene dicho su nombre, a excepción de los caciques de Tahdziú y de los más que concurrieron y no supo sus nombres. Y responde.

Preguntado qué tiempo habrá que intentó declararse por rey de esta provincia y cuál era el día que tenía señalado para matar a todos los españoles, dijo: que no ha más de un mes que determinó coronarse por rey de toda la provincia, pero que no había determinado el día que había de matar a todos los españoles. Y responde.

Preguntado de qué brujería se valió para engañar a los indios que le obedecieron por rey, a quién nombró por sucesor de la corona y qué otros empleos repartió a los caciques convocados y a los principales de Cisteil y qué profeta nombró, diga los nombres sin faltar a la verdad, dijo: que no se valió de brujería alguna porque no lo usa y que no nombró sucesor alguno ni tampoco repartió oficios a los caciques que convocó ni menos a los indios principales, que no nombró tales profetas. Y responde.

Preguntado a qué hora dio muerte al capitán don Tiburcio Cosgalla el viernes veinte de noviembre y a los demás españoles que le acompañaban, qué número de indios le acompañó a esta maldad y qué hicieron con dicho capitán y demás compañeros que les dieron muerte, dijo: que no asistió a la muerte del capitán, que quien le dio a este y a los demás fueron los indios de Cisteil que eran como cincuenta, que no supo lo que hicieron de dicho capitán ni de sus compañeros, que quien podrá dar razón de todo es el teniente de Cisteil que es un indio tuerto que se halla aquí preso entre ellos, que como entre cinco o seis de la tarde hicieron la muerte, que el no haberse hallado en esta función fue porque había ido a su posada a comer y a buscar su ropa para volver al convento. Y responde.

Y por ser ya tarde se suspendió esta confesión para proseguirla mañana. Y la firmó su señoría, merced e intérprete. 
Crespo, licenciado Maldonado, Pedro Cervera intérprete general. Don Joseph Domingo Pardio escribano mayor de gobernación y guerra.

Prosigue.

En la ciudad de Mérida a nueve de diciembre de mil setecientos sesenta y uno, dichos señores gobernador y capitán general y su teniente, para proseguir la confesión que antecede, se constituyeron en la real cárcel presente yo el escribano mayor de gobierno, hicieron comparecer al dicho Joseph Jacinto Uc de los Santos Canek de quien mediante lengua de dicho intérprete recibieron juramento que hizo por Dios nuestro señor y una cruz en forma de derecho, en cuya virtud se le hicieron las preguntas siguientes:

Preguntado qué porción de pólvora y balas tenía en Cisteil para matar a los españoles, qué número de indios tenía para dar la batalla que dio, a cuántos tiros repartió a cada fusilero y cuántos tenía de éstos y qué otras armas manejaban dichos indios, dijo: que no tenía pólvora ni plomo alguno y que no tenía más que cincuenta indios, que no habían más que veinte y cinco fusiles y que las demás armas eran palos ahusados. Y responde.

Preguntado cómo dice no se halló en la muerte del capitán ni supo lo que hicieron de él ni de sus compañeros ni que no tenía pólvora ni balas y que no tenía más que cincuenta indios cuando la batalla —el día veinte y seis de noviembre — contra la majestad católica, ni más escopetas que veinte y cinco, cuando consta en estos autos que él mató al capitán con los demás indios, que los mandó echar en una sahcabera, le mandó cortar las manos y las colgó al culo por rabo, apropiándose para sí todas las alhajas, dinero, oro y armas, y que el día de la batalla repartió a cuatro tiros de pólvora y balas a doscientos fusileros y que dicho día tenía mil y doscientos indios, diga la verdad, no falte a la religión del juramento, dijo: que no sabe lo que contiene la pregunta. Y responde.

Preguntado cómo dice que no ha convocado más que los pueblos y dos ranchos que lleva citados cuando consta por declaración de Francisco Puc que también había mandado a citar a los pueblos de Teabo, Maní, a sus caciques, a los reformados de Maxcanú, Yotholín, a los mayorales de las estancias de Uxmal y Xocneceh, que esto mismo —en careo que se le hizo con dicho Francisco Puc - se lo mantuvo en su cara y lo convenció, que asimismo el confesante dijo en Cisteil —en la puerta de la iglesia leyendo un papel de apuntes— que estaba esperando a los pueblos de Tixcacaltuyú, Tahdzibilchén, Ichmul, Sabán, Uaymax, Chunhuhub, Polyuc, Tela, Ekpetz, Tepich, Chikindzonot, Tekax, Yotholin, Bolonchén y a los caciques reformados de Maxcanú con todo su pueblo, que todos los referidos aceptaron la convocatoria, que también dijo el confesante que el cacique del barrio de San Cristóbal de esta ciudad había admitido la conjuración ofreciendo que iría al real de Cisteil y que caso que no lo ejecutara así se juntarían aquí con él los rebelados, dijo: que todos los pueblos que se han mentado en la pregunta los ha convocado, unos él por sí personalmente y otros por cartas, y que todos admitieron la conjuración y que a los caciques de los barrios de esta ciudad ni a los escribanos ni maestros de capilla de ellos ni al de Santa Catarina no ha escrito ni convocádolos ahora ni en tiempo alguno. Y que dicha convocación habrá seis meses que la comenzó y que para mediada la seca, como quien dice por la cuaresma, entraron en esta ciudad y que asimismo citó a Peto, quien aunque no concurrió pero consintió y que no sabe de otros pueblos. Que quien podrá dar razón de todo es el 
teniente de Cistel a quien tiene citado y que no sabe más de lo que se contiene en la pregunta. $\mathrm{Y}$ responde.

Preguntado cómo con poco temor de Dios nuestro señor y del rey ha cometido un delito tan grave, si sabe la pena que merece por semejante maldad, dijo: que no sabe, que lo que sabe es que ha pagado sus tributos.

Y habiéndosele hecho otras preguntas y repreguntas tocantes a esta causa, dijo: que no sabe más que lo que tiene declarado y que es la verdad so cargo de su juramento en que se afirmó y ratificó. No supo firmar, hiciéronlo su señoría, merced y dicho intérprete.

Crespo, licenciado Maldonado, Pedro Cervera intérprete general. Don Joseph Domingo Pardio escribano mayor de gobernación y guerra.

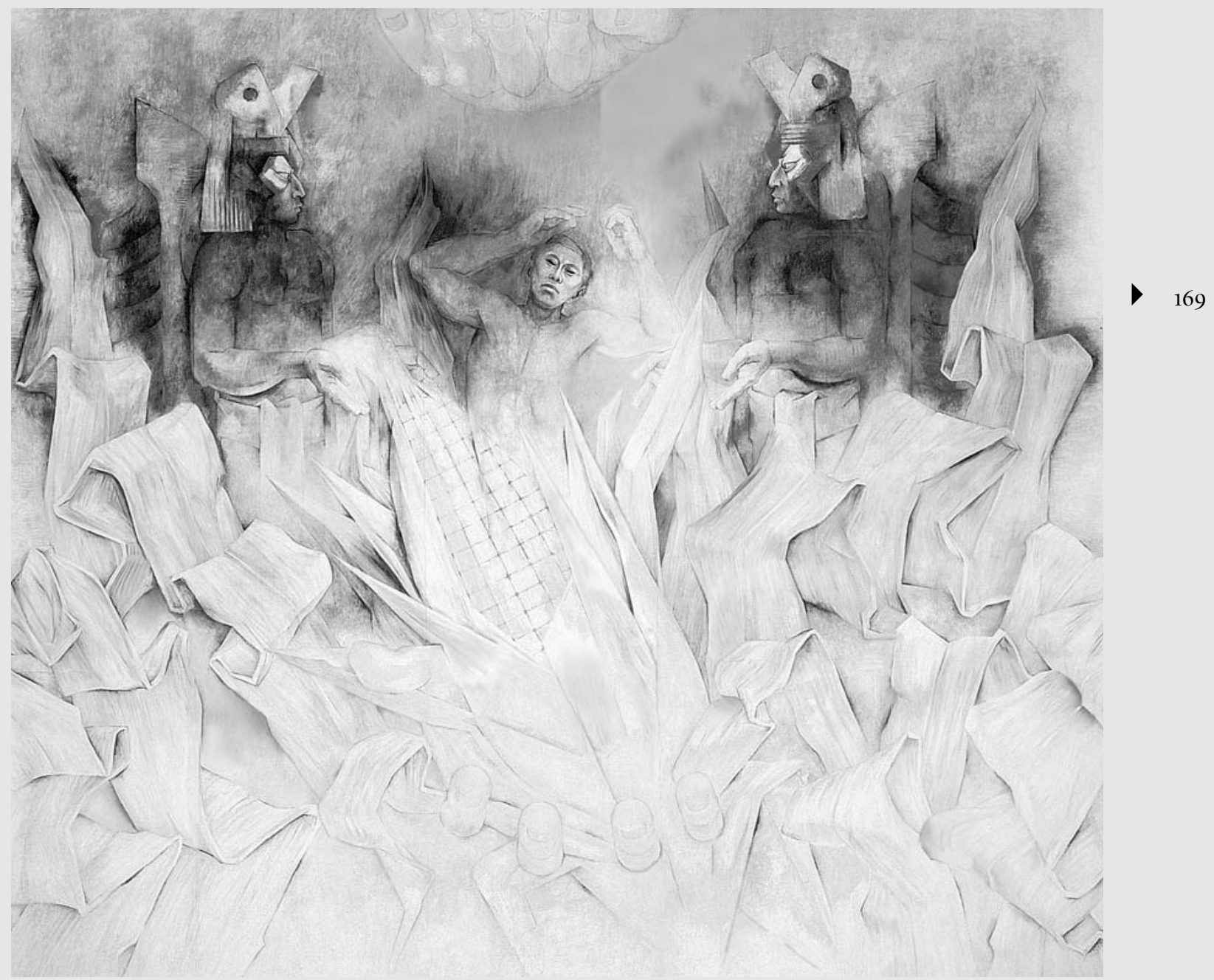

Fernando Castro Pacheco, El Mayab eterno (cosmogonía maya). 